\title{
Treatment Outcome Of Malaria And Associated Factors Among Adults Admitted In Arba Minch General Hospital 2015-2018, Southern Nation Nationality And People Region, Ethiopia
}

Gesila Endashaw Yesera ( $\square$ gesila8484@gmail.com )

Arbaminch uiversity https://orcid.org/0000-0002-4657-6422

Hussen Mekonnen Asfaw

Addis Ababa University College of Health Sciences

Solomon Kassa Bekele

Arbaminch university college of medicine and health sciences

Negalegn e Getahun Dinegd

Adis Ababa University college of medicine and health sciences

Research

Keywords: Severe malaria, death

Posted Date: June 22nd, 2020

DOI: https://doi.org/10.21203/rs.3.rs-36161/v1

License: (c) (1) This work is licensed under a Creative Commons Attribution 4.0 International License.

Read Full License 
Treatment Outcome Of Malaria And Associated Factors Among Adults Admitted In Arba Minch General Hospital 2015-2018, Southern Nation Nationality And People Region, Ethiopia,

${ }^{1}$ Gesila Endashaw Yesera (gesila8484@gmail.com, or Gesila.endashaw@amu.edu.et) ${ }^{2}$ Dr. Hussen Mekonnen Asfaw (hussen_mk@yahoo.com) ${ }^{1}$ Solomon Kassa (Solomonkassa44@amu.edu.et) ${ }^{2}$ Negalegn Getahun Dinegde (negalign99@gmail.com)

${ }^{1}$ Arbaminch University, college of medicine and health sciences school of Nursing

${ }^{2}$ Addis Ababa University College of Health sciences, school of nursing and Midwifery 


\begin{abstract}
Bachground: Malaria is a protozoan disease transmitted by the bite of infected female Anopheles mosquitoes. Progression to severe and fatal disease is largely but not entirely confined to Plasmodium falciparum infections. Despite remarkable progress in recent years, malaria remains a leading cause of sickness and death across much of sub-Saharan Africa. Malaria disproportionately impacts the rural poor, typically people who must walk for miles to seek treatment.
\end{abstract}

Methods: Institution based retrospective cross-sectional study was conducted in Arba Minch General Hospital on February 2019. Data was collected from patient record whom admitted with severe malaria in the past 4 years from Sep. 2015 - September 2018. Data was entered to Epidata 3.1. And then exported to SPSS version 25 for analysis. Bivariate and multivariate logistic regression was computed to assess statistical association between the outcome variable and independent variables using Odds Ratio; significant of statistical association was tested using $95 \%$ confidence interval $(\mathrm{CI})$ and p value $(<0.05)$.

Result: Out of 422 patients with severe malaria intended to be included in the study, 387 cases were actually involved with response rate of $91.7 \%$. The mortality rate associated with severe malaria in the year between 2015-2018 at Arba Minch General Hospital was $5.7 \%$. Co-morbidity, impaired consciousness and acidosis were significantly associated with mortality, at significant level of $\mathrm{P}<0.05$.

Conclusion: co-morbidity, impaired consciousness and Acidosis were found to be poor prognostic indicators for patients with severe malaria, so priority should be given for those patients who came with such manifestations.

Key words: Sever malaria, death. 


\section{Background}

Malaria is a protozoan disease transmitted by the bite of infected female Anopheles mosquitoes $(1,2)$. Six species of the genus Plasmodium cause nearly all malarial infections in humans. These are Plasmodium falciparum, Plasmodium vivax, two morphologically identical sympatric species of Plasmodium ovale (curtisi and wallikeri), Plasmodium malariae, and - in Southeast Asia - the monkey malaria parasite Plasmodium knowlesi. While almost all deaths are caused by P. falciparum malaria, P. knowlesi and occasionally P. vivax can also cause severe illness(2).

Infection with malaria parasites may result in a wide variety of symptoms, ranging from absent or very mild symptoms to severe disease and even death. Malaria disease can be categorized as uncomplicated or severe (complicated). In general, malaria is a curable disease if diagnosed and treated promptly and correctly(3).

Progression to severe and fatal disease is largely but not entirely confined to P. falciparum infections Although they contribute much less than P. falciparum to the global burden of severe malaria, both P. vivax and P. knowlesi can also cause severe disease and they do kill(4).

In high-transmission areas, the risk for severe falciparum malaria is greatest among young children and visitors (of any age) from nonendemic areas. In other areas, severe falciparum malaria is more evenly distributed across all age groups(5).

The risk for severe vivax malaria is greatest among young children and people with comorbid conditions. Severe disease is rare in temperate areas and in returned travellers. It occurs in relatively high-transmission areas with chloroquine resistance. P. knowlesi malaria occurs mainly on the island of Borneo but has been reported in other South-East Asian countries. Local residents and travellers to or from this region are at risk for infection. It is transmitted mainly in forests and along forest fringes (5).

High parasitaemia is undoubtedly a risk factor for death from falciparum malaria, but the relation between parasitaemia and prognosis varies according to the level of malaria transmission. In low-transmission areas, mortality from acute falciparum malaria begins to increase with parasite densities over $100000 / \mu 1$ ( 2.5\% parasitaemia), whereas in areas of 
higher transmission much higher parasite densities may be well tolerated. Parasitaemia $>20 \%$ is associated with a high risk in any epidemiological context(5).

According to $2014 \mathrm{WHO}$ criteria, severe malaria is defined as one or more of the following, occurring in the absence of an identified alternative cause, and in the presence of P. falciparum asexual parasitaemia(4):

1. Impaired consciousness: A Glasgow Coma Score $<11$ in adults

2. Acidosis: Severe acidosis manifests clinically as respiratory distress - rapid, deep and laboured breathing

3. Hypoglycaemia: Blood or plasma glucose $<2.2 \mathrm{mM}(<40 \mathrm{mg} / \mathrm{dl})$

4. Severe malarial anaemia: A haemoglobin concentration $<5 \mathrm{~g} / \mathrm{dl}$ or a haematocrit of $<15 \%$

5. Prostration/extreme weakness: inability to walk or sit up without assistant. This is the milder and benign end of the neurological manifestations spectrum, potentially dangerous unless treated urgently.

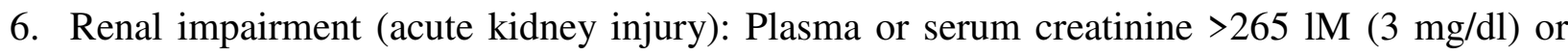
blood urea $>20 \mathrm{mM}$

7. Jaundice: Plasma or serum bilirubin $>3 \mathrm{mg} / \mathrm{dl}$

8. Pulmonary oedema: Radiologically confirmed, or oxygen saturation $<92 \%$ on room air with a respiratory rate $>30 / \mathrm{min}$, often with chest indrawing and crepitations on auscultation

9. Significant bleeding: Including recurrent or prolonged bleeding from nose gums or venipuncture sites; haematemesis or melaena

10. Shock: Compensated shock is defined as capillary refill $\geq 3 \mathrm{~s}$ or temperature gradient on leg (mid to proximal limb), but no hypotension.

11. Hyperparasitaemia: P. falciparum parasitaemia $>10 \%$

The World malaria report 2017 showed that progress against malaria has stalled in many countries, and that the world was unlikely to achieve the WHO Global technical strategy for malaria morbidity and mortality targets for 2020. Since the beginning of global malaria fight still now the attempts are on a cross road(6).

In 2017, an estimated 219 million cases of malaria occurred, compared with 239 million cases in 2010 and 217 million cases in 2016. Even though there was an estimated 20 million fewer 
malaria cases in 2017 than in 2010, data for the period 2015-2017 highlight that no significant progress in reducing global malaria cases was made in this timeframe(6).

Although there was remarkable progress in recent years, malaria remains a leading cause of sickness and death across much of sub-Saharan Africa. Majorly malaria impacts the rural poor, typically people who must walk for miles to seek treatment. It is also a leading cause of absenteeism among employees, increased health care spending, decreased productivity, and approximately 50 percent of all preventable school absences in Africa. Malaria helps to trap families in a vicious cycle of disease and poverty(7).

Majority of malaria cases in 2017 were in the WHO African Region (200 million or 92\%), followed by the WHO South-East Asia Region with 5\% of the cases and the WHO Eastern Mediterranean Region with $2 \%$.Fifteen countries in sub-Saharan Africa and India carried almost $80 \%$ of the global malaria burden. Five countries accounted for nearly half of all malaria cases worldwide: Nigeria (25\%), Democratic Republic of the Congo (11\%), Mozambique (5\%), India (4\%) and Uganda (4\%). In 2017, there were an estimated 435000 deaths from malaria globally, The WHO African Region accounted for 93\% of all malaria deaths in 2017(6).

The 2017 WHO age adjusted death rates estimates associated with severe malaria reported that, in Africa total of 43 countries including Ethiopia are under high death rate.

Ethiopia account 5.43 deaths per 100,000(8).

Malaria is a major public health problem in Ethiopia despite relatively low malaria prevalence compared to most other malaria-endemic countries in Africa. Unstable malaria transmission patterns make Ethiopia prone to focal and multifocal epidemics that have on occasion caused catastrophic public health emergencies. Malaria is seasonal in most parts of Ethiopia, with variable transmission and prevalence patterns affected by the large diversity in altitude, rainfall, and population movement(9).

In 2014/2015, the total number of laboratory-confirmed plus clinical malaria cases in Ethiopia were 2,174,707(10). Another study conducted on mortality rates of malaria in Ethiopia during 2015 showed the total number of deaths associated with malaria was 1561 which is a 
significant number suggesting an attempt should be done to bring down deaths(11). So this shows that malaria is a problem on Ethiopia.

Some studies conducted in different regions of the Ethiopia suggested that malaria is still a problem in the country, for instance a retrospective study conducted in Amhara region concluded that: malaria continued to be one of the major public health problem. Moreover, there was no successive yearly reduction in its prevalence. Therefore, efforts are required to reduce the disease burden through continuous monitoring and evaluation of control measures in the study area(12).

The 2014-2020 Ethiopians national malaria strategic plan for malaria put that by 2020, achieve near zero malaria death in all malarious areas of the country(25). So to achieve this strategic plan conducting this study is one helpful contribution.

Methods: The study was conducted at Arba Minch General Hospital. Arba Minch General Hospital is one of the hospitals in Southern Ethiopia, Gamo Gofa zone, $505 \mathrm{~km}$, south of Addis Ababa with an elevation of 1285 meters ASL(26). Arba Minch General Hospital officially commenced its functioning in 1963, and has currently been delivering its health care services in the medical, surgical, gynecological, pediatrics wards, and through a total of 324 beds. Institution based retrospective cross-sectional study was used.

All adult patients' with malaria admitted randomly selected patient charts were from September 2015 to September 2018. Incomplete patient charts will be excluded. Sample size was determined by the number of patients whom admitted during the time period from September 2015 to August 2018 and it is found that a total of 3,727 patients with malaria were admitted in this time period. Sample size was calculated using single population proportion sample size determination method by assuming $50 \%$ of case fatality to yield the maximum representative sample size with $95 \%$ confidence interval. Total of 422 complete patient charts were included in the study.The records and charts of patients with malaria over the past four years period, from September 2015 to September 2018 was retrieved from the record room by taking medical record number from adult medical register and discharge registration log book. After consecutive listing medical record numbers diagnosed as malaria were sampled randomly. Simple random sampling using computer generated random numbers was used. Infact medical visit is random by its nature for sake of involving the whole four years document 
sampling was found to be better than counting. Data was collected using a adopted checklist which enables to dig out every possible information from patient's record.(18)(19). Four data collectors trained for data extraction. Each day of data collection the collected data was checked for its completeness by supervisor. Possible correction measures taken soon. The data was entered to Epi Data- version 3.1. And then exported to SPSS version 25 for analysis. Descriptive statistic was performed to summarize results using texts and tables. In Bivariate analysis variables having value less than 0.25 was entered in to multivariable logistic regression to assess statistical association between the outcome variable and independent variables and biological plausibility was considered to select variables too. Odds Ratio was used as measure association using $95 \%$ confidence interval $(\mathrm{CI})$ and $\mathrm{p}$ value $(<0.05)$.

Result : In this study a total of $\mathbf{4 2 2}$ samples were considered first but it actually included a total of $\mathbf{3 8 7}$ sample with a non-response rate of $\mathbf{8 . 3 \%}$. From the total of 387 patients chart diagnosed for malaria in the year between September 2015 to 2018, was used for analysis. About 231(59.7\%) and 156(40.3\%) were male and female respectively. The mean age was 26.16 (SD \pm 9.9$)$, majority of respondents $289(74.7 \%$ ) lie in between the age group 18-27 years. Almost many 361(93.3\%) of patients with malaria came from area of high transmission and 26(6.7\%) from low transmission area. Table 1 below shows details of socio demographic variables. Out of 387 cases, almost all $357(92.2 \%$ ) of patients had come to hospital in a $\leq 5$ days since the onset of sign and symptoms but 30(7.8\%) of patients had come lasting more than 5 days. From the total of 387 cases of malaria, more than half 214(55.3\%) had single WHO defined severity indicator and the remaining 173(44.7\%) had developed sever malaria and had 2 or more overlapping severity indicator during admission. Of all 387 cases of malaria more than half $365(94.3 \%)$ had recovered and 22(5.7\%) had died. The gender specific case fatality was $5.1 \%(12 / 231)$ in males and 6.4\% (10/156) in females. See table 1

Table 1: frequency distribution of independent variables Arba Minch general hospital from September 2015-september 2018, N=387.

\begin{tabular}{|l|l|l|l|}
\hline Variable & Category & Frequency & \% \\
\hline Age & $18-27$ & 289 & 74.7 \\
\cline { 2 - 4 } & $28-37$ & 36 & 9.3 \\
\cline { 2 - 4 } & $38-47$ & 43 & 11.1 \\
\hline
\end{tabular}




\begin{tabular}{|c|c|c|c|}
\hline & $48-57$ & 11 & 2.8 \\
\hline & $>=58$ & 8 & 2.1 \\
\hline \multirow[t]{2}{*}{ Sex } & Male & 231 & 59.7 \\
\hline & Female & 156 & 40.3 \\
\hline \multirow{3}{*}{$\begin{array}{l}\text { Place of residency } \\
\text { based on } \\
\text { transmission rate }\end{array}$} & $\begin{array}{l}\text { low transmission (Altitude >2000 m. } \\
\text { ASL) }\end{array}$ & 26 & 6.7 \\
\hline & $\begin{array}{l}\text { High transmission(Altitude }<2000 \\
\text { m. ASL) }\end{array}$ & 361 & 93.3 \\
\hline & Total & 387 & 100.0 \\
\hline \multirow{2}{*}{$\begin{array}{ll}\text { Time } & \text { before } \\
\text { admission } & \end{array}$} & $<=5$ days & 357 & 92.2 \\
\hline & $>5$ days & 30 & 7.8 \\
\hline \multirow[t]{3}{*}{$\begin{array}{l}\text { Patients } \\
\text { manifestation } \\
\text { during admission }\end{array}$} & Prostration/extreme weakness & 232 & 38.3 \\
\hline & Hyperparasitaemia & 185 & 30.5 \\
\hline & Severe malarial anaemia & 49 & 8.1 \\
\hline
\end{tabular}

\begin{tabular}{|l|l|l|l|}
\hline & Impaired consciousness & 45 & 7.4 \\
\hline & Acidosis & 25 & 4.1 \\
\hline & Renal impairment & 24 & 4.0 \\
\hline & Shock & 19 & 3.1 \\
\hline & Hypoglycaemia & 18 & 3.0 \\
\hline & Significant bleeding & 6 & 1.0 \\
\hline Treatment taken & Jaundice & 3 & 0.5 \\
\hline & Quinine & 53 & 13.7 \\
\hline $\begin{array}{l}\text { Site of drug } \\
\text { administration }\end{array}$ & Artisunate & 334 & 86.3 \\
\hline
\end{tabular}




\begin{tabular}{|c|c|c|c|}
\hline & Intramuscular & 3 & .8 \\
\hline \multirow{2}{*}{$\begin{array}{l}\text { Is there any other } \\
\text { associated disease }\end{array}$} & No & 344 & 88.9 \\
\hline & Yes & 43 & 11.1 \\
\hline \multirow{2}{*}{$\begin{array}{ll}\text { Time } & \text { before } \\
\text { admission } & \end{array}$} & $<=5$ days & 357 & 92.2 \\
\hline & $>5$ days & 30 & 7.8 \\
\hline \multirow{10}{*}{$\begin{array}{l}\text { Patients } \\
\text { manifestation during } \\
\text { admission (one or } \\
\text { more alternatine is } \\
\text { possible) }\end{array}$} & Prostration/extreme weakness & 232 & 38.3 \\
\hline & Hyperparasitaemia & 185 & 30.5 \\
\hline & Severe malarial anaemia & 49 & 8.1 \\
\hline & Impaired consciousness & 45 & 7.4 \\
\hline & Acidosis & 25 & 4.1 \\
\hline & Renal impairment & 24 & 4.0 \\
\hline & Shock & 19 & 3.1 \\
\hline & Hypoglycaemia & 18 & 3.0 \\
\hline & Significant bleeding & 6 & 1.0 \\
\hline & Jaundice & 3 & 0.5 \\
\hline \multirow[t]{3}{*}{ Treatment taken } & Quinine & 53 & 13.7 \\
\hline & Artisunate & 334 & 86.3 \\
\hline & Intravenous & 384 & 99.2 \\
\hline $\begin{array}{l}\text { Site of drug } \\
\text { administration }\end{array}$ & Intramuscular & 3 & .8 \\
\hline \multirow{2}{*}{$\begin{array}{l}\text { Is there any other } \\
\text { associated disease }\end{array}$} & No & 344 & 88.9 \\
\hline & Yes & 43 & 11.1 \\
\hline \multirow{3}{*}{$\begin{array}{l}\text { Type of malarial } \\
\text { species }\end{array}$} & Falcipharum & 350 & 90.4 \\
\hline & Vivax & 30 & 7.8 \\
\hline & Both & 7 & 1.8 \\
\hline
\end{tabular}

Table extension

\begin{tabular}{|l|l|l|l|}
\hline \multirow{2}{*}{$\begin{array}{l}\text { Time before } \\
\text { admission }\end{array}$} & $<=5$ days & 357 & 92.2 \\
\cline { 2 - 4 } & $>5$ days & 30 & 7.8 \\
\hline
\end{tabular}




\begin{tabular}{|c|c|c|c|}
\hline \multirow{10}{*}{$\begin{array}{l}\text { Patients } \\
\text { manifestation } \\
\text { during admission } \\
\text { (one or more } \\
\text { alternatine is } \\
\text { possible) }\end{array}$} & Prostration/extreme weakness & 232 & 38.3 \\
\hline & Hyperparasitaemia & 185 & 30.5 \\
\hline & Severe malarial anaemia & 49 & 8.1 \\
\hline & Impaired consciousness & 45 & 7.4 \\
\hline & Acidosis & 25 & 4.1 \\
\hline & Renal impairment & 24 & 4.0 \\
\hline & Shock & 19 & 3.1 \\
\hline & Hypoglycaemia & 18 & 3.0 \\
\hline & Significant bleeding & 6 & 1.0 \\
\hline & Jaundice & 3 & 0.5 \\
\hline \multirow{2}{*}{ Treatment taken } & Quinine & 53 & 13.7 \\
\hline & Artisunate & 334 & 86.3 \\
\hline \multirow{2}{*}{$\begin{array}{l}\text { Site of drug } \\
\text { administration }\end{array}$} & Intravenous & 384 & 99.2 \\
\hline & Intramuscular & 3 & .8 \\
\hline \multirow{2}{*}{$\begin{array}{l}\text { Is there any other } \\
\text { associated disease }\end{array}$} & No & 344 & 88.9 \\
\hline & Yes & 43 & 11.1 \\
\hline \multirow{3}{*}{$\begin{array}{l}\text { Type of malarial } \\
\text { species }\end{array}$} & Falcipharum & 350 & 90.4 \\
\hline & Vivax & 30 & 7.8 \\
\hline & Both & 7 & 1.8 \\
\hline \multirow[t]{2}{*}{ +Outcome } & Recovered & 365 & 94.3 \\
\hline & Died & 22 & 5.7 \\
\hline \multirow[t]{2}{*}{ Jaundice } & yes & 3 & .8 \\
\hline & no & 384 & 99.2 \\
\hline \multirow[t]{2}{*}{ Bleeding } & yes & 6 & 1.6 \\
\hline & no & 381 & 98.4 \\
\hline \multirow[t]{2}{*}{ shock } & yes & 19 & 4.9 \\
\hline & no & 368 & 95.1 \\
\hline Hyperparasitaemia & Yes & 185 & 47.8 \\
\hline
\end{tabular}




\begin{tabular}{|l|l|l|l|}
\cline { 2 - 4 } & no & 202 & 52.2 \\
\hline Total & & 387 & 100.0 \\
\hline
\end{tabular}

Table 2. Descriptive statistics crosstab of sex, outcome and age category with different severity parameters of malaria September 2015-september 2018, Arbaminch hospital, $(n=387)$.

\begin{tabular}{|c|c|c|c|c|c|c|c|c|c|}
\hline & \multicolumn{2}{|l|}{$\operatorname{sex}$} & \multicolumn{2}{|l|}{ outcome } & \multicolumn{2}{|c|}{ Age cat } & \multirow[t]{2}{*}{ Tot. } & \multirow[t]{2}{*}{$\%$} \\
\hline & & female & Male & Recovered & Died & $<40$ & $>40$ & & \\
\hline \multirow[t]{2}{*}{ Acidosis } & yes & 15 & 10 & 20 & 5 & 24 & 1 & 25 & 6.45 \\
\hline & no & 216 & 146 & 345 & 17 & 311 & 51 & 362 & 93.5 \\
\hline \multirow[t]{2}{*}{ hypgycaemia } & yes & 9 & 9 & 16 & 2 & 18 & 0 & 18 & 4.7 \\
\hline & no & 147 & 222 & 349 & 20 & 317 & 52 & 369 & 95.3 \\
\hline \multirow[t]{2}{*}{ anemia } & yes & 20 & 29 & 46 & 3 & 44 & 5 & 49 & 12.66 \\
\hline & No & 136 & 202 & 319 & 19 & 291 & 47 & 338 & 87.33 \\
\hline \multirow{2}{*}{$\begin{array}{l}\text { Renal } \\
\text { impairment }\end{array}$} & yes & 12 & 12 & 23 & 1 & 20 & 4 & 24 & 6.2 \\
\hline & no & 144 & 219 & 342 & 21 & 315 & 48 & 363 & 93.79 \\
\hline \multirow[t]{2}{*}{ Comorbidity } & yes & 22 & 21 & 32 & 11 & 32 & 11 & 43 & 11.11 \\
\hline & no & 134 & 210 & 333 & 11 & 303 & 41 & 344 & 88.88 \\
\hline
\end{tabular}

\section{Factors affecting death associated with severe malaria}

Table 3. Below shows, impaired consciousness, acidosis, and co-morbidity found to be significantly associated with death related to severe malaria, $\mathrm{p}$ value less than 0.05 .

Cases that have impaired consciousness are 4.175 times more likely to die than those who don't have ( $\mathrm{CI}=1.265-13.782, \mathrm{P}=0.019)$. Cases that have acidosis are 5.735 times more likely to die than those who don't $(\mathrm{CI}=1.265-13.782, \mathrm{P}=0.019)$. And cases that had comorbidity are 13.163 times more likely to die than those who don't have $(\mathrm{CI}=4.168$ -

41.575, $\mathrm{P}=0.000)$.

Table 4: Factors affecting death associated with malaria among adults admitted in Arba Minch general hospital during 2015-2018.

\begin{tabular}{lllllll}
\hline Variable & Category & \multicolumn{2}{l}{ COR $(\mathbf{9 5 \%}$ CI) } & \multicolumn{2}{l}{ AOR (95\% CI) } & \multicolumn{2}{l}{ P-value } \\
\hline Age $>=40$ & Yes & 4.169 & $(1.655-10.503)$ & 2.776 & $(0.825-9.339)$ & 0.099
\end{tabular}




\begin{tabular}{|c|c|c|c|c|c|c|}
\hline & No & 1 & & 1 & & \\
\hline \multirow{2}{*}{$\begin{array}{l}\text { Place of residency based on } \\
\text { transmission rate }\end{array}$} & Low transmission & 1 & & 1 & & \\
\hline & High transmission & 3.465 & $(1.080,-11.119)$ & 0.265 & $\begin{array}{l}(0.058- \\
1.218)\end{array}$ & 0.088 \\
\hline \multirow[t]{2}{*}{$\begin{array}{l}\text { Time before admission } \\
\text { >5days }\end{array}$} & Yes & 6.939 & $\left(\begin{array}{ll}2.574 & 18.703\end{array}\right)$ & 2.231 & $\begin{array}{l}(0.643 \\
7.744)\end{array}$ & 0.206 \\
\hline & No & 1 & & 1 & & \\
\hline \multirow[t]{2}{*}{ Impaired consciousness } & Yes & 7.857 & $\left(\begin{array}{ll}3.167 & 19.494\end{array}\right)$ & 4.175 & $\begin{array}{l}(1.265 \\
13.782) *\end{array}$ & 0.019 \\
\hline & No & 1 & & 1 & & \\
\hline \multirow[t]{2}{*}{ Acidosis } & Yes & 5.074 & $(1.699-15.155)$ & 5.735 & $\begin{array}{l}(1.339 \\
24.554) *\end{array}$ & 0.018 \\
\hline & No & 1 & & 1 & & \\
\hline \multirow[t]{2}{*}{ Shock } & Yes & 3.444 & $(0.923-12.850)$ & 0.921 & $(0.159-5.351)$ & 0.927 \\
\hline & No & 1 & & 1 & & \\
\hline \multirow[t]{2}{*}{ Hyperparasitaemia } & Yes & 0.390 & $(0.149-1.018)$ & 0.370 & $\begin{array}{l}(0.114- \\
1.204)\end{array}$ & 0.099 \\
\hline & No & 1 & & 1 & & \\
\hline \multirow[t]{2}{*}{ Treatment taken } & Artisunate & 1 & & 1 & & \\
\hline & Quinine & 2.537 & $(0.946-6.808)$ & 2.573 & $(0.741-8.929)$ & 0.137 \\
\hline \multirow[t]{2}{*}{$\begin{array}{l}\text { Is there any other associated } \\
\text { disease }\end{array}$} & Yes & 10.406 & $(4.184-25.880)$ & 13.163 & $\begin{array}{l}(4.168- \\
41.575)^{*}\end{array}$ & 0.000 \\
\hline & No & 1 & & 1 & & \\
\hline
\end{tabular}

\section{Conclusion:}

In Ethiopia clinical malaria incidence rate has dropped from an average of 43.1 cases per 1000 population annually between 2001 and 2010 to 29 cases per 1000 population between 2011 and 2016. Death associated with malaria has declined from 2.1 deaths per 100,000 population between 2001-2010 to 1.1 deaths per 100,000 population between 2011-2016 given the new policy of free malaria prevention and treatment which address the poor whom are more prone to the infection (28). 
There is no recent study conducted in Ethiopia on treatment outcome of severe malaria among adults. Thus this study had tried to assess treatment outcome of severe malaria among adults admitted in Arba Minch general hospital during 2007 -2010 EC. Southern Ethiopia. It is necessary to identify factors influencing treatment outcome of severe malaria and reduce the risk of mortality associated with the disease.

The present study included 387 patients with severe malaria and revealed that $59.7 \%$ of cases were male and $40.3 \%$ were female with higher male to female ratio of $1.48: 1$ which is nearly similar to a study conducted in India Maharashtra which shows a male to female ratio of 2.23:1(19). And unlike to a study conducted in Gondar referral hospital with male to female ratio of $0.83: 1(18)$.

In this study, adult population age group between 18-27 (74.7\%) are more presented with severe malaria, similar to a study conducted in Gondar referral hospital which is higher among age group 20-29 (36.5\%) and in India Maharashtra which is again higher among age group 20-29 $(34.55 \%)(18,19)$. This occurred most likely because of an active working age group which makes them vulnerable to infection.

The current study revealed that almost all (93.3\%) of cases with severe malaria had come from higher transmission area which is an altitude of less than $2000 \mathrm{~m}$. above sea level(23). This shows it is fact that malarial infection is higher in malaria endemic area.

Out of 387 cases 214(55.3\%) cases had single severity indicator and 173(44.7\%) cases had two or more overlapping severity indicators. Taking in consideration of the overlapping features of severe malaria presenting sign and symptoms, prostration/extreme weakness was seen in the majority of cases accounted 38.3\% and hyper-parasitemia seen among $30.5 \%$ of the cases. This is consistent with the findings of a study conducted in Malawi Blantyre Queen Elisabeth hospital(16). Other presenting features in decreasing order were severe malarial anemia, impaired consciousness and acidosis.

Regarding of the malarial species, P. falciparum predominates which accounted for $90.4 \%$ of the cases and P. vivax accounted $7.1 \%$ of the cases which is comparable to the study conducted in Gondar referral hospital(18). 
In this study the overall mortality rate associated with severe malaria was 5.7\% (22/387) which is lower than similar study conducted in Gondar referral hospital during 2006 and a prospective observational study conducted Maharashtra, India which was $28.4 \%$ And $13.63 \%$ respectively $(18,19)$. This difference in mortality shows an improvement on the treatment regimen possibly the newly used Artemisinin derivative (artisunate) antimalarial treatment.

Case fatality rate was highest among patients with co-morbidity $(25.6 \%)$ than late comers lasting >5 days (23.3\%), impaired consciousness (22.2\%), acidosis (20\%) and shock (15.7\%). In the current study impaired consciousness and acidosis were two of poor prognostic indicators which was consistent with the study conducted in Gondar referral hospital(18). Comorbidity is another poor prognostic indicator which was again consistent with findings of a study conducted in western Thailand (20).

This study showed that malaria is one of a major burden of Arba Minch general hospital. Except for pulmonary edema and convulsion many of the WHO severity indicators were observed among cases admitted during period. The overall mortality rate associated with severe malaria was 5.7\% . Co-morbidity, impaired consciousness (GCS $<11)$ and acidosis were the major determinant of treatment outcome (death). Malaria prevention measure should be endorsed intensively. Malaria mapping might be needed to prioritize areas. Hospital administration should work on providing an intensive care unit to treat patients who came with severe and complicated malaria. As the study indicated death is somehow high hospital malaria management is need focus. This study observed those who come without complication developed complication while they were admitted or first visited the hospital should identify and treat patients with severe malaria especially for those who came with impaired consciousness, acidosis and comorbidity. Create awareness for patients who visit the hospital on the prevention of the transmission of malaria and prompt visit of health care setting is to be focused. Set a program on malaria during health education and they should strength existing program. Patients must come to health facility as early as possible whenever they feel sick. Future studies should conduct a prospective study which helps to include every possible independent variables and come with more findings. The current study showed impaired consciousness, acidosis and comorbidity were the major determinant of 
mortality but doesn't show why those patients most likely to die than the others, so further study is needed to investigate the reason behind.

Ethical approval and consent to participate: The proposal was approved by the Addis Ababa University Institutional Ethical Review Board. An official letter was written from the Addis Ababa University to Gamo Gofa Zone Health department and Arbaminch general hospital. During data collection letter was written to patient record unit.

\section{Consent for publication}

Not applicable

\section{Availability of data and materials}

The datasets text and audio used and/or analyzed during the current study can be obtained from the corresponding author on reasonable request.

\section{Competing interest}

The authors declare that they have no competing interests

\section{Funding}

Addis Ababa University offered financial support to carry out the study.

\section{Authors' contributions}

SK, HM and NG, are participated in conceiving the study and wrote the proposal. GE participated in analysis. Data extraction and prepared manuscript. Conducted data collection together. All the authors had read and approved the final draft of this manuscript.

\section{Acknowledgment}

First and for most, we would like to forward our gratitude to Addis Ababa university college of medicine and health sciences who the research project.

\section{References}

1. Hinkle, L. Cheever H. text book of medical surgical nursing. 13th ed. 2014.

2. J.Larry Jameson DLKDLL, editor. principles of internal medicine. 20th ed. 2018. $15751579 \mathrm{p}$.

3. CDC report on severe malaria [Internet]. Available from: https://www.cdc.gov/malaria/about/disease 
4. Health I, Malaria RB. WHO Severe Malaria. 2014;19:7-131.

5. WHO. Management of severe malaria, a practical hand book. 3rd ed. 2012.

6. World malaria report 2018. 2018.

7. President US, Initiative M. The President's Malaria Initiative. 2018;(April).

8. WHO. Age adgusted death rates estimates [Internet]. 2017. Available from: http://www.worldlifeexpectancy.com/cause-of-death/malaria/by-country/

9. EPHI. Ethiopian National malaria indicator survey. 2015.

10. FMOH health and health related indicators. Version 1. 2007;1:1-66.

11. Deribew A, Dejene T, Kebede B, Tessema GA, Melaku YA. Incidence, prevalence and mortality rates of malaria in Ethiopia from 1990 to 2015 : analysis of the global burden of diseases 2015. Malar J. 2017;1-7.

12. Alelign A, Tekeste Z, Petros B. Prevalence of malaria in Woreta town, Amhara region, Northwest Ethiopia over eight years. 2018;1-6.

13. Marks ME, Armstrong M, Suvari MM, Batson S, Whitty CJM, Chiodini PL, et al. Severe imported falciparum malaria among adults requiring intensive care : a retrospective study at the hospital for tropical diseases, London. BMC Infect Dis. 2013;

14. Mundhe R, Karale MS, Usendi C, Yadav S. Clinical profile and outcome of severe P . Falciparum malaria. 2016;3(4):1034-8.

15. Sagaki P, Thanachartwet V, Desakorn V, Sahassananda D, Chamnanchanunt S, Chierakul W, et al. Clinical Factors for Severity of Plasmodium falciparum Malaria in Hospitalized Adults in Thailand. 2013;8(8).

16. Segula D, Frosch AP, Sanjoaquin M, Taulo D, Skarbinski J, Mathanga DP, et al. Prevalence and spectrum of illness among hospitalized adults with malaria in Blantyre, Malawi. 2014;1-6.

17. Abdallah TM, Abdeen MT, Ahmed IS, Hamdan HZ, Magzoub M, Adam I. Severe Plasmodium falciparum and Plasmodium vivax malaria among adults at Kassala Hospital , eastern Sudan. 2013;1-7.

18. Mengistu G, Diro E. Treatment outcome of severe malaria in adults with emphasis on neurological manifestations at Gondar University. 2007;(May).

19. Gupta BK, Gupta A, Nehra HR, Balotia HR, Meena SL, Kumar S. Clinical Profile and Prognostic Indicators in Adults Hospitalized with Severe Malaria Caused by Different Plasmodium Species. 2015;45-50. 
20. Newton PN, Stepniewska K, Dondorp A, Silamut K, Chierakul W, Krishna S, et al. Prognostic indicators in adults hospitalized with falciparum malaria in Western Thailand. Malar J [Internet]. 2013;12(1):1. Available from: Malaria Journal

21. Dondorp AM, Lee SJ, Faiz MA, Mishra S, Price R, Tjitra E, et al. The Relationship between Age and the Manifestations of and Mortality Associated with Severe Malaria. Clin Infect Dis. 2008;

22. Hanson J, Lee SJ, Mohanty S, Faiz MA, Anstey NM, Charunwatthana P, et al. MAJOR ARTICLE A Simple Score to Predict the Outcome of Severe Malaria in Adults. 2010;50:679-85.

23. NATIONAL STRATEGIC PLAN FOR MALARIA PREVENTION CONTROL AND ELIMINATION IN ETHIOPIA 2011 - 2015. (August 2010,Addis Ababa).

24. Wikipedia [Internet]. Available from: https://en.wikipedia.org/wiki/Arba_Minch

25. Admasu K, Ghebreyesus TA. Ethiopia Malaria Policy Landscape 2017 notable events in national policy and financing for malaria 2014 - 2020 National Strategic Plan goals and targets. 2020;(December 2017):1-7.

26. Arba Minch [Internet]. 2018. Available from: http//en.m.wikipedia.org/wiki/Arba_Minch

27. Bin A, Zubairi S, Nizami S, Raza A, Mehraj V, Rasheed AF, et al. Severe plasmodium vivax Malaria in Pakistan. 2013;19(11):1851-4.

28. Taffese HS, Hemming-schroeder E, Koepfli C, Tesfaye G, Lee M, Kazura J, et al. Malaria epidemiology and interventions in Ethiopia from 2001 to 2016. 2018;1-9. 